\title{
Human Security Workers Deployed in Austere Environments: A Brief Guide to Self-Care, Sustainment, and Productivity
}

\author{
Thomas F. Ditzler ${ }^{1, *}$, Patricia R. Hastings ${ }^{2}$ and Abigail D. Hoeh ${ }^{1}$ \\ ${ }^{1}$ Department of Psychiatry, Tripler Army Medical Center, 1 Jarrett White Rd, Honolulu, HI, 96859, USA; \\ E-Mail: abigail.d.hoeh.ctr@mail.mil (ADH) \\ ${ }^{2}$ Joint Chiefs of Staff (JCS) Surgeon's Office, United States Department of Defense (DOD), 1400 Defense \\ Pentagon, Washington, DC, USA; E-Mail: patricia.r.hastings2.mil@mail.mil \\ * Corresponding Author: E-Mail: thomas.f.ditzler.civ@mail.mil; Tel.: +1 8084331246 \\ Submitted: 15 September 2014 | In revised form: 24 December 2014 | Accepted: 15 January 2015 | \\ Published: 14 April 2015
}

\begin{abstract}
Since the early 1990s, the human security movement has sought to expand the concept of security beyond the traditional military defense of national borders to focus on the intra-state security needs of populations at the individual level. Specific initiatives frequently address problems of population health, ethnic conflict, religious extremism, human rights, environmental or natural disasters, and other critical issues. For expatriate human security workers in the field, the environment may present meaningful challenges to their wellbeing and productivity. This can be especially so for those who have relatively more experience in academic, business, or administrative settings, and less in the field. The authors' goal is to illuminate practices that have demonstrated their efficacy in enhancing wellness, sustainment, and productivity for human security and other humanitarian and development workers deployed to austere environments. The content represents a synoptic consensus of best general practices and guidance from a range of resources comprising United Nations agencies and activities, national and international non-governmental organizations (NGO's), private volunteer organizations (PVO's), national military services, and international business concerns.
\end{abstract}

Keywords: humanitarian; human security; non-governmental organizations; population health; private volunteer organizations

\section{Introduction}

From its beginnings in the early 1990's, the human security movement has engaged a stunningly broad constellation of challenges. Human security workers may represent disciplines of anthropology, interna

(C) 2015 by the authors; licensee Librello, Switzerland. This open access article was published under a Creative Commons Attribution License (http://creativecommons.org/licenses/by/3.0/). 
tional relations, environmental science, ethics, health, engineering, economics, law, or other professional fields. For those who engage in human security work in the field, environments are often austere. Workers may confront their mission in the context of civil strife, limited or depleted natural resources, endemic disease, meager or absent health care, unsafe transportation, inadequate public health assets including water and sanitation, and other critical infrastructure. Research on psychological distress among such workers indicates that chronic exposure to such environmental stressors, including the suffering of others, is associated with negative mental health outcomes, including depression, anxiety, and "burnout" characterized by long-term exhaustion and diminished interest. These outcomes are, in turn, associated with decreased work satisfaction and productivity [1]. To effectively meet the challenges of these environments, workers require strong support from their sponsoring organizations; the best preparation emerges from a transparent and interactive agency-worker partnership that embraces a shared responsibility for mission outcome. Specific agency-based support should include pre-employment screening of potential workers, provision of mission-specific education, training, and ongoing worksite support in the field. Whatever the specific activities of the agency, planning for success should include thorough worker preparation in self-care and sustainment. Specific skills typically include healthy practices of personal hygiene, diet, physical fitness, cultural adaptation, socialization, and development of effective stress management strategies. These skills are mission-essential for all deployed workers. The advantage of healthy, self-sustaining workers is reflected in greater mission success, improved job satisfaction and increased worker longevity [1].

\section{Pre-Deployment Issues}

If being engaged a new organization, workers are advised to contact current or former workers familiar with the organization to learn as much as possible about its leadership style and general culture, to get a clear understanding of screening, hiring, and field support procedures as well as vacation or leave policies and access to health care.

Many experienced workers make a "deployment book" to leave at home with an appropriate person. The content typically includes relevant personal information that someone else would need to contact the worker. At the very minimum this should include names and contact information of key deployment agency personnel at both the home office and in the area of operation $(A O)$, copies of the ID page of the worker's passport with several other recent pictures of him or her, and a letter of instruction on what to do if the worker is ill, detained, or missing. A more substantive document might include copies of required authorizations and permissions necessary to permit another to carry out legal, business, financial or other personal responsibilities on the worker's behalf, such as a power of attorney.

In addition, it is important for the worker to conduct a thorough background study of the AO. There is no single best way to organize the effort, but areas of focus often include the region's history, geography, social organization, political institutions, spiritual system(s), health care, transportation, important social customs and traditions, and language. Learning some of the local language is an obvious advantage in any environment. In situations with one principal language, workers can pursue pre-deployment study. There are many government, academic, and commercial sources available in a range of media.

Unfortunately, many of the languages of the field environments human security workers engage are not commonly spoken, or the number of languages or dialects commonly spoken precludes the acquisition of meaningful skills. This is especially so in settings in host communities with a large number of refugees or internally displaced persons. A properly vetted local translator is a necessity, and can also serve as a cultural informant to provide useful information on a range of issues related to important customs, traditions, and social conventions. For workers attached to organizations already in the $\mathrm{AO}$, translation and related language issues are usually managed by the sponsoring agency. In the absence of a translator, the pre-deployment language practice mentioned above can go a long way in facilitating productive social exchanges. It is a truism that workers' level of wellness, comfort, security and productivity can be largely predicted by their working knowledge of the culture around them.

\section{Health Preparation}

Health authorities recommend that basic preparation include a comprehensive pre-deployment medical exam, a review of routine personal medications, and consultation on medications indicated for potential medical threats in the $A O$ [2]. A dental exam is also considered good planning. It is worth noting that even in otherwise sophisticated military organizations, dental problems are a common cause of evacuation from the field. Hormonal changes may predispose females to gingivitis, making a dental exam more important than many may realize [3]. For routine maintenance medication, seasoned workers often take a supply that extends two months beyond the scheduled deployment. In preparation for work in arduous environments, the basics of nutrition would advise keeping a healthy weight with a BMI of 19-25, and eating a balanced diet including grains, fruits, vegetables, milks, and meats/proteins. Women need more iron, calcium and folic acid. If unable to secure these nutrients on a reliable basis, it is best to discuss possible supplements with a health care provider. 


\section{Equipment}

Proper fit and comfort of personal gear is an important, but easily neglected aspect of self-care. Most military and camping equipment items are sized for males and may need to be modified for females. Injuries to the lower back and legs of female soldiers are twice those of men [4]. Jumping from relatively low heights can cause knee and hip injuries. Women are more prone to stress fractures of the hip and leg. Females involved in extreme athletic endeavors can have similar problems due to low body fat, loss of menstruation, and hormonal changes which can weaken bones and predispose to stress fractures [5]. One of the factors contributing to these types of injuries may be equipment, which is not typically designed for females. [6]. A female may have difficulty carrying the same load in the same way as a male, often because she has a shorter back. The best backpack for females is often one that has adjustable shoulder straps, a chest strap, and a waist belt to place some of the bag's weight on the hips. Because a female's shoulders may not be as broad as a male's it is often beneficial for a greater amount of weight to be placed on the hips.

Ankle injuries are also more common in women than in men. If at all possible, women should select boots made for the female feet. Females have higher arched and semi-curved feet. In contrast, the male heel and ankle is typically wider due to the pull of the calf muscles and musculature [7]. Before deploying, women should ensure that foot-gear is well broken in. Also, a supportive sports bra can make long treks much more comfortable and decrease back and shoulder pains. Most females with field experience would advise a pull over the head sports bra to lengthen its use, as harsh washing can break or rip the eyelets used to fasten a regular bra.

\section{Safety and Security}

Among seasoned humanitarian workers there is a common saying: "if you don't have security, you don't have anything". This aphorism is especially true for emergency workers responding to large-scale natural or technologic humanitarian disasters, or those who are working in areas of armed conflict or other general social strife. Clearly, workers deployed to these areas are in exceptional circumstances, and security measures are unique to each environment. Typically, security practices involve responses reflecting the collaborative efforts of the supporting humanitarian agencies/organizations, the host government, and in some instances, military personnel or civilian police (see Appendix A for more information about physical security in high risk areas). In stable environments, unavoidable hazards, threats, and vulnerabilities require a clear and consistent risk management strategy. The most effective security plans start with detailed background knowledge of the $\mathrm{AO}$; there is no substitute for situational awareness of the environment and culture. Below are a number of principles, precepts, and practices that have demonstrated their utility in maximizing collective security and wellness for program leadership and workers.

- Safety and security is everyone's concern at both the organizational and personal level. A useful aphorism is: "have the plan, know the plan, carry out the plan".

- Safety plans and rules must be communicated to all; acceptable and unacceptable risks must be clearly defined along with procedures for exceptional circumstances (e.g.travel at night, traveling alone, etc.)

- Ensure that safety and security issues are an integrated part of administrative and supervisory meetings. This will reify the expectation of shared security vigilance among colleagues

- Have clear contingency plans for special threat situations including severe weather, important infrastructure failure, civil disruption, or other security conditions

- Communication practices are critical and should include standardized training for communication equipment, procedures and terminology.

- Know relevant local laws and customs, especially about what to do in cases of a vehicular collision, pedestrian accident, or inadvertent property damage. Especially in rural tribal settings or areas embracing transitional justice, the customary response may be harsh.

- Do not defer routine vehicle maintenance, and ensure that all vehicles have up-to-date maps on board along with serviceable mobile communications equipment.

- If possible, have secure vehicle parking and maintain an environmentally appropriate medical kit on board.

- Personal wellness is a large part of safety. In addition to physical fitness, adequate sleep and appropriate nutrition, workers can increase safety for themselves and others by abstaining from recreational drug use, and moderating alcohol.

- For those concerned about the need for emergent medical care or the possibility of rapidly deteriorating security conditions, consider rescue and evacuation insurance (see Appendix B for more information on several well-known firms).

\section{General Hygiene in the Field}

The routine conveniences of daily hygiene materials and practices may be much less available in the field. Important hygiene practices to maintain are: dental care, regular bathing, hydration maintenance, avoidance of simple sugars, and abstaining from alcohol and tobacco products. Fluoride toothpaste is advised in most cases. In the absence of toothpaste, table salt or baking soda may work well, or use a cloth and water to wipe over each tooth surface to help avoid debris build-up. 
Ideally, all workers should have access to a way to wash every day to avoid disease, parasites and skin infections. Showers are preferred to baths to avoid urinary tract infections (UTIs). Minimal requirements for bathing are: a secure environment, at least one quart of water, soap, and proper drainage. If no shower facilities are available and water use is restricted, commercially available wet-wipes can ensure a minimum level of hygiene until a shower is available. Wet-wipes may also be used as toilet paper if this comfort is not available.

A common hygiene problem for workers (and for women in particular) is difficulty urinating in environments with less than optimal privacy or in situations in which it could be dangerous to disrobe. In responding to this, workers may sometimes resort to strategies that are sub-optimal for peak performance and health. For example, some may decide to voluntarily minimize fluid intake to avoid urination, which could increase the likelihood of UTIs. If one will be away from any medical facilities it may be practical to have an antibiotic prescribed for use if needed. In addition to increasing the likelihood of a UTI, water restriction can cause dehydration. Voluntary water restriction may not be subjectively perceived as dangerous to the individual owing to the belief that the sensation of thirst will automatically cue them when it is time to hydrate. In reality, anyone with a clear sensation of thirst is already dehydrated. Controlled studies indicate that among women, even mild dehydration is associated with headache, lowering of mood, increased fatigue, increased perception of task difficulty, and impaired concentration [8-10]. More severe restriction can also lead to heat injury including heat exhaustion or heat stroke, which can be fatal. The risk of heat injury may be increased in very dry environments in which the sensation of perspiration may not provide a clue for fluid loss [11]. Urine retention also increases the likelihood of bladder injury in the instance of blunt impact or deceleration injury (e.g. fall, or vehicular mishap) as the pelvis or abdomen can more easily traumatize the distended bladder. Fluid intake is critical to peak performance and, though this may be considered in hot environments, it can be problematic in cold regions where women can face the danger of cold exposure because of the need to disrobe more fully to urinate.

It is not unusual to have some change in menstrual period length or flow in a physically or emotionally stressful environment. Women are encouraged to have enough sanitary supplies for at least 30 days if resupply is predictable and longer if resupply is not assured. Some external irritation may occur in hot environments, but cornstarch or a thin layer of petroleum jelly may improve comfort. Pads can also be used if stress incontinence may be an issue. For women who use tampons, cardboard applicators are usually a better choice than plastic because plastic applicators can cause micro-abrasions in the vaginal mucosa and are not bio- degradable. Both tampons and pads can do double duty when used as dressing or to occlude bleeding sites.

\section{Climate Issues}

It has long been known that a high level of physical fitness is a key element in worker safety and productivity. As a practical matter, physically fit workers are less likely to get sick or injured; and they recover more quickly when illness or injury occurs. In addition, active physical conditioning helps workers to acclimatize to the environment. This is especially important in environments of extreme heat or cold including desert environments, where daily cycles of extreme temperatures are common. Caution is advised when exercising in very hot or cold weather as chance of injury tends to increase with temperature extremes. In general, women do not tend to perspire as quickly or easily as males [12]. The way the female body adapts to heat relies on the principal of a smaller total body mass combined with the larger surface area to body mass ratio. This explains why women will often do better than men in hot topical (wet) environments, but not as well initially in hot desert (dry) locations where perspiring can make a difference in acclimatization (US Army Public Health Command, 2010). Also, women typically have lower finger temperatures and higher rates of peripheral vascular disorders that could make them more susceptible to peripheral cold injury.

\section{Social Acculturation and Gender Roles}

The process of adaptation to a new and sometimes jarringly different social environment has traditionally been referred to as "culture shock". Hopefully workers will have availed themselves of basic background information about the work environment and the process of cultural adjustment. In many areas, traditional gender role expectations may place meaningful constraints on working women, even if they are expats in a humanitarian role. Expat female and male colleagues in these areas are well advised to have a clear understanding of culturally acceptable interaction in a shared space.

Customary dress is often conservative for both men and women. This may involve covering the limbs, (i.e. long pants for males and long sleeves and long pants or long skirts for females), and often includes covering the hair for females. These modes of dress can make one's job more difficult physically and emotionally. For example, if acceptable clothing comprises a full-length, dark colored robe, heat may become a meaningful problem. Likewise, covering the ears can decrease the ability to hear the spoken word or localize other sounds. Full facial coverage can also impair peripheral vision and the ability to see what is near ones feet. In some areas, women wear tight fitting shorts under their skirts to ensure if there is an inadvertent move- 
ment of the skirt that their upper legs will not be seen.

Norms for behavior may not allow male or female workers to talk to the opposite gender. Females may not be allowed to be in the company of males who are not a relative; in some instances, a male aid worker may put a local female at risk by speaking with her or being in her company. Age can also be a difficulty with regard to the youth of a country adapting to foreign languages more quickly than adults and change the dynamics of a family or clan if the younger children or adolescents are acting as interpreters.

Body language can be a powerful force for good or ill. In many circumstances, there are subtleties that must be briefed to those going into an area. It is especially important to be aware of norms about physical touching, and in many cultures there a certain gestures that are best avoided. Other normative communication issues might concern gaze behavior. In many western cultures, looking another person in the eyes is often considered a sign of sincerity; in many other settings it may be considered rude or aggressive. Also, the social expectations of gaze behavior may be different depending on the gender of the speakers. Similarly, asking about another's spouse or family may be viewed as friendly or intrusive. It is worth noting that many cultures also have strong customs, traditions, and social rules governing the processes of gift giving; once again, a little cultural homework can go a long way. This is especially so if the host country is also accommodating refugees or internally displaced persons, where multiple standards may apply.

\section{Emotional Self Care}

This skill set has been variously referred to as stress management, resiliency, personal wellness, mental health, emotional well-being, psychological hardiness, and other terms. Research confirms that humanitarian workers, especially those responding to large scale disasters, have high rates of subsequent psychological distress. These frequently include a range of mood disorders, anxiety disorders, and in some instances spiritual or philosophical problems, sometimes involving loss of hope or purpose $[1,13,14]$.

Although the field work of human security workers may not routinely engage the magnitude and complexity of career disaster responders, the cumulative effects of their work can still be emotionally challenging. Whatever the specific mission, it is clear that evidence from a number of studies reveals the most common source of psychological distress is the persistent exposure to the suffering or deprivation of others (Antares Foundation, 2012; Brunette, 2011). An important but less striking source of strain may include separation from family and friends, physically demanding work, different language and working through translators, unusual foods, crowding and lack of privacy, different social customs (especially concerning gender roles), harsh climate, or a lack of accustomed comforts. Over time the otherwise fairly ordinary inconveniences can produce an emotionally corrosive effect sufficient to compromise general wellness and productivity.

Based on a review of the literature, Blanchetiere [14] proposed that causes of stress may be thought of under four general headings: 1) situational factors, including personal security, health risks, and demands of the population; 2) job related factors, comprising living conditions, cultural change; workload, colleague relations, and job security; 3 ) organizational climate, involving program roles and expectations, management style and worker support; 4) personal risk factors, incorporating poor self-care, psychological vulnerabilities, unrealistic expectations and motivation, and lack of experience. The sources of stress, therefore, are complex, interrelated, persistent, and idiosyncratic. The key to management lies in having in place an individualized self-care program focused on health maintenance and increased comfort. The plan embodies the worker's aggregate knowledge, skills, experience, beliefs, behaviors, plans, and attitudes that contribute to the maintenance of well-being. Effective plans begin in the pre-deployment phase, during which the worker reflects on the personal values, goals and expectations they attach to their efforts. These insights can help to identify the substance of their motivation and facilitate the earnest assessment of their particular strengths and limitations that shape specific self-care plans. Below are some self-care ideas that have proved useful for many.

- Monitor your mood, and establish mutual support relationships; share your thoughts and feelings with trusted coworkers at appropriate times.

- Make a point of planning an exercise schedule and stick to it. Because the operational tempo may be high, it is important to block out specific time to ensure you maximize the advantages of a regular physical care regimen.

- Real time electronic communication (social media, FaceTime, Skype, etc.) can facilitate a sense of connectedness with home.

- Keep a log (diary) of thoughts, feelings and activities; this often helps in processing your activities and may later provide an instructive source of reflection on your experiences.

- Sharing humor can provide welcome relief from the stress, but it is important to keep things positive. If the tone turns negative or angry, it can compromise trust and erode the collaborative spirit.

- Personalize your living quarters with photos, significant keepsakes, and other reminders of home; it helps maintain a sense of continuity and attachment - When possible, seek recreation away from the work area.

- Even if you will not be on site for an extended period, it is generally a good idea to unpack your bags to lend an element of order and predictability to your personal environment.

- Be careful about the use of alcohol; the pressures 
of field work can potentially lead to an unhealthy increase in consumption. Recreational drug use is clearly contraindicated.

\section{Coming Home}

As the mission winds down, workers are often invigorated by thoughts of returning home to their family, friends and customary lifestyle. They may reflect on their endeavors, and the relationships they have developed with colleagues and those they sought to help. Workers often look forward to having time to consider what they have learned and accomplished, and to sharing their experiences with others. Indeed, being part of a team with a shared goal in service to others can be a great source of healthy pride. However, there is often sadness about departing.

Sometimes the feelings can be surprisingly intense. Departing workers and those they served all benefit from making adequate time to get closure, and saying goodbye or making plans to stay connected. In some circumstances this may involve a communal activity or formal event; in others, it may be more personal. Whatever form it takes, the departure process reifies the value of what has been done and acknowledges the contributions of all.

On returning home, workers embrace the challenges of reconnecting with their previous world. Especially for those who have less experience in foreign placements, or who have been away for a longer time, the process can be surprisingly disquieting. Although formal research is scarce, comments of field workers from diverse missions reveal a number of common themes that may emerge for returnees. Below are some of the most frequent of these with some advice from humanitarian mission leaders [13].

- As a returnee, understand that the homecoming may be less eventful and rewarding than you had imagined.

\section{References}

[1] Cardozo BL, Crawford CG, Eriksson C, Zhu J, Sabin M, Ager A, Foy D, Snider L, Scholte W, Kaiser R, Olff M, Rijnen B, Simon W. Psychological distress, depression, anxiety, and burnout among international humanitarian aid workers: a longitudinal study. PloS one. 2012;7(9):e44948.

[2] Brunette GW. CDC Health Information for International Travel 2012: The Yellow Book. New York, NY, USA: Oxford University Press; 2011.

[3] WebMD. Hormones and Oral Health. Available from: http://www.webmd.com/oral-health/hormonesoral-health.

[4] US Army Public Health Command. A guide to female soldier readiness. USAPHC (Prov) technical guide 281. Available from: http://phc.amedd.army.mil/ Pages/default.aspx.
- Once home, get lots of rest. Jet lag only lasts a few days, but returning to the pace and activities of home may require some adaptation. Give yourself time to adjust; don't try to do too much too fast. This is especially important if you are returning to work.

- Family and friends can be problematic if their need for your attention inadvertently overburdens you. It may be necessary to diplomatically explain your need for some undisturbed time.

- You may want to talk a lot about your experience and find that others are simply disinterested, or that they don't seem to connect with the magnitude of what you have experienced. They may be much more interested in telling you what has happened for them during your absence.

- In other cases, you may find the questions of others to be intrusive. You may experience anger or frustration with those who seem insensitive or unsympathetic to what may have been a life changing experience for you.

- These contradictory feelings, while troublesome, are part of the readjustment process; as a general rule, try to be at least as understanding of yourself as you would be of someone else in your position.

\section{Conclusions}

A large and expanding body of research clearly validates the critical role of individual worker wellness in the success of human security field missions. From pre-deployment planning, through mission responsibilities in the AO, to the return home, both workers and agencies clearly benefit from a thoughtful plan for self-care. The rewards of worker self-sustainment can be measured in terms of both mission success on the ground and long term worker wellness. Hopefully the authors' efforts will provide some useful guidance on how to approach the process.

[5] AAOS. American Academy of Orthopaedic Surgeons. OrthoInfo. Stress Fractures. Available from: http://orthoinfo.aaos.org/topic.cfm?topic $=$ a00112.

[6] Simpson KM, Munro BJ, Steele JR. Backpack load affects lower limb muscle activity patterns of female hikers during prolonged load carriage. Journal of Electromyography and Kinesiology. 2011;21(5):782-788.

[7] Wilkerson RD, Mason MA. Differences in men's and women's mean ankle ligamentous laxity. The Iowa orthopaedic journal. 2000;20:46-48.

[8] Armstrong LE, Ganio MS, Casa DJ, Lee EC, McDermott BP, Klau JF, Jimenez L, Le Bellego L, Chevillotte $E$, Lieberman HR. Mild dehydration affects mood in healthy young women. The Journal of Nutrition. 2012;142(2):382-388.

[9] Ganio MS, Armstrong LE, Casa DJ, McDermott $B P$, Lee EC, Yamamoto LM, Marzano S, Lopez RM, Jimenez L, Le Bellego L, Chevillotte $E$, Lieberman HR. 
Mild dehydration impairs cognitive performance and mood of men. British Journal of Nutrition. 2011; 106(10):1535-1543.

[10] Masento NA, Golightly M, Field DT, Butler LT, van Reekum CM. Effects of hydration status on cognitive performance and mood. British Journal of Nutrition. 2014;111(10):1841-1852.

[11] US Army. FM 90-3/FMFM 7-27. Desert Operations. Headquarters Department of the Army US Marine Corps. Technical manual. 2003. Available from: http://armypubs.army.mil/doctrine/dr_pubs/dr_a/pdf/f

\section{Appendix A: Security Planning Resources}

Rogers, C., \& Sytsma, B. (1999). World Vision Security Manual.

Van Brabant, K. (2000). Operational security management in violent environments. Overseas Development Institute.

Adventist Development and Relief Agency. Guidelines for Developing a Security Plan. Retrieved from http://www.adrasouthpacific.org/site_data/109/assets /0038/2161/Guidelines_for_Develpoing_a_Security_ Plan.doc

\section{Appendix B: Rescue and Evacuation Resources}

Rescue and evacuation insurance through Global Rescue (globalrescue.com)

International Medical Group (imglobal.com)

Adventure Sports Insurance

(adventuresportsinsurance.com) m90_3.pdf.

[12] Buono MJ, Sjoholm NT. Effect of physical training on peripheral sweat production. Journal of Applied Physiology. 1988;65(2):811-814. Available from: http://jap.physiology.org/cgi/reprint/65/2/811.

[13] Antares Foundation. Managing stress in humanitarian workers; Guidelines for good practice. Available from: https://www.antaresfoundation.org/.

[14] Blanchetiere P. Resilience of humanitarian workers. 2006. Available from: http://www.dochas.ie/ Shared/Files/4/resilience-of-aid-workers.pdf.

International SOS (internationalsos.com)

\section{Appendix C: Aid Worker Training Resources}

All resources accessed on 23 December 2014

http://www.jhsph.edu/research/centers-andinstitutes/center-for-refugee-and-disasterresponse/education_training/HELP/

http://www.goinginternational.com/ https://www.icrc.org/eng/resources/documents/misc/ help_course.htm

http://www.who.int/hac/techguidance/training/course s/en/

http://reliefweb.int/training

http://www.disasterready.org/about

http://www.sphereproject.org/blog/free-onlinehumanitarian-training-resources/ 